\title{
A METHOD OF BRIEF GROUP PSYCHOTHERAPY
}

\author{
MAJ J R BIRD, MRCPsych, DPM, RAMC \\ Queen Elizabeth Military Hospital, Woolwich
}

SUMMARY: The development, over the past two years, of brief group psychotherapy as a treatment approach with military psychiatric patients is described. The tactics and techniques involved in the method are particularly emphasised.

The recurrent themes of service life, identity difficulties and nuclear family disturbances were noted in all groups and the concept that the Army might be experienced as a "one parent family" is explored. The value of the group representing both a microcosm of military society and a family unit, being used as a testing situation is high-lighted.

\section{Introduction}

Group psychotherapy for the treatment of soldiers developed during World War II at Northfield Military Hospital. Foulkes ${ }^{1}$ who was a principal pioneer of this movement saw the hospital group as a focus for change from passivity to activity with increased spontaneity and self confidence. Group treatment was viewed either as an approach to aid return to duty or as a worthwhile method of treating soldiers, needing help, prior to discharge from the Army and resettlement in civilian life.

Writing at a later time, Foulkes ${ }^{2}$ developed further the adaptation of group analytic techniques to the needs of military life. Certainly the upsurge of group psychotherapy treatment in the American Army was felt by Arthur $^{3}$ to ow/e much to the British experience, and brief group psychotherapy lasting for 21 weekly sessions was undertaken by Moffett and Stoklosa ${ }^{4}$ with socially anxious unassertive young veterans.

There are, as Friedman ${ }^{5}$ observed, many soldiers with limited ego skills who cannot adjust to military life. Foley ${ }^{b}$ acknowledged this by undertaking group treatment with newly enlisted airmen, accepting that some groups were primarily for the rehabilitation of men to be discharged, whilst seeking to retain others who had developed and matured as a result of group involvement. His objective criterion for the value of the group approach was retention in the Air Force for at least one year after group therapy.

Two years ago group psychotherapy was reintroduced firstly at the Royal Victoria Hospital, Netley and on that hospital's closure, in the Psychiatric Division of the Queen Elizabeth Military Hospital. The original aims of Foulkes and other workers are essentially unchanged.

A considerable number of servicemen and women are referred to hospital who do not have a psychiatric disorder amenable to drug treatment. They present a variety of neurotic symptoms. Behaviour disturbance and personality disorder that can only be helped by a psychotherapeutic approach. Often, as $\mathrm{Kibel}^{7}$ notes, the object of brief hospitalization has been to remove a patient from an environ- 
mental stress. This frequently occurs in the military community where patients present unable to cope either with the demands of service life or with their own personal difficulties. Efficiency has been impaired and their own personal integrity and ego ideal disturbed and distorted.

This paper based on the experiences of the past two years outlines a technique for brief group psychotherapy and discusses some aspects of group dynamics particularly relevant to group work in a military environment.

\section{Aim}

The principal aim in the use of group psychotherapy with certain selected patients was always the provision of a specific, realistic and worthwhile treatment approach. It was hoped that every patient joining a group would gain in some degree:

i. Alleviation of symptoms. ii Increasing social effectiveness. iii Heightened self awareness.

At the same time the requirement to provide teaching and training to junior psychiatrists and psychiatric nurses was also met by giving them experience in a specialised therapeutic technique. A further aim was to stimulate interest, foster skill and develop a greater awareness of group methods by further training both within and outside the psychiatric division.

An additional aim was the employment of limited treatment resources as efficiently and economically as possible. Lindsay ${ }^{8}$ developed the economical aspects of group treatment and also stated, "not the least advantage of group therapy, is the opportunity it offers the military for much needed research in group dynamics". This aspect of group work has so far received little attention.

\section{Selection of group members}

The majority of patients referred for group treatment came from wards within the Division, some from Area psychiatrists or Naval psychiatric colleagues, whilst a few were direct referrals, having heard about group treatment from others.

Not surprisingly the male to female ratios was $4: 1$ which made balancing group membership impossible. Ages ranged from 18 to 47 years and ranks between private and major were represented in the groups. Civilians and dependants are now offered group places and the more central location of the unit has increased the number of service patients able to attend on an outpatient basis.

Criteria for selection of group members has deliberately not been stringent and out of approximately 60 patients referred for group treatment only four were rejected as unsuitable. It is worth stressing that less than 20 of these patients would have been considered as suitable for intensive individual psychotherapy and even this number would have severely taxed, if not overwhelmed, available treatment resources.

When considering a patient for inclusion in a group the following basic considerations were applied:

i Is this patient likely to benefit in some measure from a group? ii Is he motivated to attend regularly throughout the group? iii Is he prepared to give 
in a sharing experience with others? iv Is he able to understand and utilize an interpretation?

The types of disturbance, symptoms and personality problems brought to the group varied considerably.

Example 1

Gunner A, aged 28 years. He felt everyone was against him, talking about him of being homosexual. His paranoid state had led to excess drinking, social isolation and depression.

Group aim: To help him find his true sexual identity and to experience acceptance for himself in a group setting.

Example 2

W/Private B, aged 21 years. Complete inability to make decisions as a result of an over-protective mother and restricted family background.

Group aim: 'To increase sense of self and accept responsibility for her own decisions.

Example 3

$\mathrm{Q} /$ Lieutenant $\mathrm{C}$, aged 27 years. Repeated failed romances had led to depression and overdose. She was eventually involved in destructive relationships.

Group aim: To understand her inappropriate object choices.

Example 4

Warrant Officer D, aged 46 years. Pathological reaction since the death of his wife three years earlier. Very severe episodes, withdrawal and fear of new relationships.

Group aim: To confront his need to remain grieving.

The most common referral was the young soldier experiencing difficulty in handling relationships, adjusting to service life and coping with mood disturbance. Frequently there was a history of self injury, disturbed family background and an absence of meaningful figures in current life.

Service motivation was not an issue in the selection of patients, the intention at all times was to provide what Chance" calls a "concrete anchorage" for patients with ego deficits by membership of the group. Mirin ${ }^{10}$, reviewing ineffective military personnel, pointed out that the tendency in the military was to emphasise to the individual "who he is" and "what he does". The purpose of the group was to reverse this process and make the individual responsible for answering these two questions himself.

\section{Group arrangements}

\section{Method}

Groups normally comprised eight patients, usually six men and two women, and was closed to new members. The group met twice a week for a total of 20 sessions, each session lasting one hour. Particular effort was made to meet in the same room, on the same days and at the same time and to avoid therapist absence. This helped the group to value the group process and emphasised developing group identity, structure and boundaries, which were further fostered by the use of a circular seating arrangement with similar chairs and an absence of 
formality. The patients and the co-therapists invariably chose to introduce themselves by Christian names. The writer preferred to be addressed by his rank or as doctor. The term 'sir' in fact only intruded in one group and was of value in understanding an individual's difficulties, as shown in this exchange:

\section{Vignette 1}

Sapper $\mathrm{Y}$ could not bring himself to address a senior Warrant Officer as anything but 'Sir'. He remained blocked and rather uncommunicative, polite yet distant, until his difficulty was interpreted as a defence against hostile feelings towards authority figures. This released a flood of rage and resentment at his father which could at last be worked with.

Notwithstanding the informality of these groups, it was quite noticeable how easily the normal courtesies of rank were retained within the ward setting outside the group.

\section{Co-therapy}

The needs of training demanded that the writer acted as therapist for these early groups working with three different co-therapists, all of whom were female commissioned Mental Nurses. Benjamin ${ }^{11}$ examined co-therapy roles especially where the nurse might be viewed as a "lower status professional" when working with a doctor. It is thus particularly satisfying to record that one of the cotherapists has subsequently run her own group with a consultant psychiatrist as co-therapist and each greatly valued the experience. The trainee psychiatrist would become in turn observer, to co-therapist, to therapist, gaining experience and confidence whilst appreciating the contribution of nursing colleagues.

Heilfron $^{12}$ noted that "intertherapist interaction is a deeply personal relationship", whilst Rabin $^{13}$ comments on the successful co-therapy relationship producing a sharing of achievement and pleasure at the mastery of conflict. This was the writer's experience. Certainly the 'wash-up' after group sessions allowed for a review of the group dynamics, an assessment of each others contribution, appropriate praise and not infrequently valid and valued criticism.

The therapist represented to group members at any one time a variety of figures both in reality as doctor and nurse, and officer representatives of a hierarchical establishment, and through transference distortions. Thus the therapist couple might also be seen as parental figures or a spouse. These views often produced a defensive posture in the group as the following illustrates:

\section{Vignette 2}

In one group all members insisted on standing up whenever we arrived and again with studied courtesy at the end of each session, despite our regularly stated wish that this should not happen. The atmosphere was oppressive and non-therapeutic, with lengthy silences. Clearly the group were perpetuating the reality of rank differences as a way of avoiding confrontation with authority. After this was repeatedly interpreted it was possible to get in touch with the struggles that many members experienced in coping with service life and discipline, and, in another dimension, parental strictures. 


\section{Vignette 3}

The majority of one all male group consistently ignored the female co-therapist, forgetting her name, talking across her and whilst listening politely to her observations did not respond. We discussed this in a 'wash-up' and eventually she directly interpreted the group's treatment of her as revealing their attitude towards women, that perhaps it represented aspects of hostility or dismissiveness which the group avoided, fearing she couldn't cope. An initial sniggering view of women as 'second rate citizens' and 'only sexual objects' was tolerated: later, insecurities in dealing with women could be more maturely reviewed.

\section{The group process}

Kanter ${ }^{14}$ made the point that, "if you look after the group the individual will look after himself". The focus in these groups, through a modified group analytic approach, was on emphasising the group as an evolving dynamic structure in which personal development followed personal involvement. As Walton ${ }^{15}$ noted, each group member contributes constructive interactions as well as psychopathology.

It was particularly necessary to avoid directing or leading these groups. Becker $e t a l^{16}$ have rightly stressed that in all groups the therapist is seen as a "high status authority figure". How much more must this be so in these officerled military groups! Each group then went through a transition period in which expectations and wish for instruction, direction and teaching had to be clarified and confronted. This was never easy, either for therapists or group members, and initial lengthy silences gave particular point to Yalom' ${ }^{17}$ wry observation that "the group begins when suddenly nothing happens".

Also it needs to be stressed, as did Berger ${ }^{18}$ writing on the anxieties of trainees undertaking group psychotherapy, that a compulsive urge to 'cure' may indicate a compulsive need to be helpful and represent a basic anxiety regarding usefulness. It is often counter-productive.

The group members were expected to own the responsibility for talking and revealing self and areas of conflict. The therapists sought to clarify and confront what was going on within the group, accepting the individual contributions and then offering the group an interpretation which all members could share. This was illustrated in the following exchanges:

\section{Vignette 4}

David was quite clearly extremely angry with his wife whilst Karen had repressed intense anger towards her mother. Yet both stressed how much they gave wife and mother; how unselfish and unstinting they were. It was interpreted to the group that there was a clear distinction between quantity and quality in what we give to others and that perhaps David and Karen were showing us that resentment ruins the quality no matter how much the apparent giving. Other members of the group might feel they also were not totally genuine in what they offered of themselves to others. 
These group interpretations allow all group members to learn from experience of others, whilst avoiding the direct confrontation of an individual, which is often experienced as intensely persecutory. It was quite noticeable how rapidly these groups accepted this style of working and gave up an original belief that only when the therapist is talking does treatment take place. Members became more poised and assured in their communications and with increasing confidence confronted both their own and other's difficulties. It was gratifying to observe the developing maturity of group exchanges and the seriousness with which the whole group process was undertaken.

\section{Discussion}

What has become clear from the various completed brief psychotherapy groups, is that two major themes - service life and nuclear family interactions - have dominated group exchanges. From a psycho-dynamic viewpoint the two were often equated. Military life, a masculine dominated society, can be conceptualized as a 'one parent family' and authority invested with Paternal attributes. However, the parental influence of the military organization has an extra dimension. It is not invested in a single figure; it is amorphous and diluted with each higher rank another paternal figure.

In such a setting identity confusion can occur. Policy decisions affecting the individual are felt to emanate not from an identifiable figure but from a system. The individual may then feel he cannot influence, as he might a parent, such a nebulous structure. The frustration, resentment and sense of challenging which brings many soldiers with problems to the medical services is analogous to the rebellious child testing out parental authority as a declaration of personal independence. It is noteworthy how often problem solving is seen by these patients in terms of only one solution - escape, leaving the Army - as the adolescent might run away from home.

These feelings were often encountered in the groups and could, usually only slowly, be understood and modified. Not infrequently an individual determined to leave the Army found service motivation restored, with subsequent return to duty.

Clearly many group members had re-experienced in the 'military family' disturbance of self that had roots in childhood. This was not surprising when much psychopathology and symptom formation is a result of failure in childparent or intersibling relationship. These were now recreated in service life and the tendency to repress conflicts, displace resentments and project blame were regularly seen in the group setting.

At the same time earlier and current dissatisfactions with the nuclear family was a constant focus for therapeutic work and it seemed that the groups served a twin purpose. Firstly, it represented a microcosm of military society with authority figures in the persons of the officer therapists and other group members as part of the military fraternity. Secondly, the closed group could be experienced as a family unit with the male and female therapists seen as parental figures and the other group members viewed as siblings. Even within the limits 
of a brief group experience, realistic and distorted attitudes could be and were, tested out.

Brief group psychotherapy seemed particularly valuable in assisting patients with communication and relationship difficulties. Scheidlinger and Pyrke ${ }^{19}$ made the interesting observation that certain highly dependent women could more freely verbalize in a group, feelings that were repressed in a one to one setting. This undoubtedly appeared the case with a number of young female soldiers and was just as true with the high percentage of schizoid individuals referred to the group. The ability to establish meaningful relationships is based on previous tested experience usually in a secure family base in which early object relations have been successfully negotiated. Many of these group members demonstrated repetitivly, failure in object choice producing gross insecurity, social isolation and ego disturbance.

The group offered these patients an opportunity to test out some of these difficulties in a setting designed to encourage free and safe expression, in an atmosphere of acceptance where non-critical and non-judgemental feedback provided an evaluation of self, and self in relationship to others. This was for most a unique opportunity which was particularly valued.

\section{Conclusion}

The value of group psychotherapy has been questioned by various writers, including Phillipson ${ }^{20}$, who felt two years' treatment was necessary for radical change and by Malan et $a l^{21}$ who said that the procedure produced generally poor results except when patients received prior individual treatment. Yet few could argue with the latter author's successful use of brief individual psychotherapy for specific symptom relief.

It is perhaps from such a dimension that brief group psychotherapy can be viewed. Seven of these groups have now been run and from a total membership of 51 patients only five patients left the groups. Undoubtedly some group members appeared to gain little, with minimal insight and no significant change in symptoms or behaviour. However, on the credit side, it is gratifying to find that others have settled back surprisingly well to military life, made readjustments in family relationships and developed a greater sense of maturity and well being. Since at no time was return to duty viewed as the specific function of the groups, it is also satisfying to find that group members have reported a more settled and confident mode of functioning on return to civilian life.

The impression that group psychotherapy is a worthwhile and valid treatment procedure, remains for the present, essentially subjective although based on reports from colleagues and a considerable number of letters. That most group members record valuing their group experience and feel that they have gained, is perhaps the best test.

\section{Acknowledgements}

I would like to express my gratitude and appreciation to my three co-therapists: Maj M Windsor, QARANC, Capt G Bradley QARANC, and Miss J MacDonald (late Capt: QARANC). Whatever $\mathrm{I}$ gave them they returned in 
greater measure. I should also like to record my thanks to those colleagues who referred patients to me and supported my efforts, not least the very loyal ward staff who cheerfully accepted a frustrating role of non-involvement with the group patients.

\section{REFERENCES}

1. Foulkes, S H (1946). Group analysis in a military neurosis centre. Lancet i, 303-306.

2. Foulkes, S H (1964). Therapeutic Group Analysis. George Allen \& Unwin. London.

3. AUthuR, R J (1978). Reflections on military psychiatry. Am J Psychiatry 135, 2-7.

4. Moffet, $L A$ and Stoklosa, J M (1976). Group therapy for socially anxious and unassertive young veterans. Int J Group Psychother 26, 421-430.

5. Friedman, H J (1972). Military psychiatry. Arch Gen Psychiatry 26, 118-122.

6. Foley, $T$ J (1970). The efficiency of group psychotherapy with 1 st term airmen at an Air Force technical training centre. Corrective Psychiatry and Journal of Social Therapy 16, 46-50.

7. KIBEL, H D (1978). The rationale for the use of group psycotherapy for borderline patients on a short term unit. Int J Group Psychother 28, 339-359.

8. LINDSAY, D G (1955). Group therapy at an Army mental hygiene centre. United States Armed Forces Medical Journal 6, 633-644.

9. CHANCE, E (1976). Some implications of variations in technique of group therapy for social controls. Int $J$ Soc Psychiatry 22, 147-152.

10. MIRIN, S M (1974). Ineffective military personnel. Arch Gen Psychiatry 30, 389-402.

11. Benjamin, S E (1972). Co-therapy: A growth experience for therapists. Int J Group Psychother 22, 199-209.

12. HeIlfroN, M (1969). Co-therapy: The relationship between therapists. Int J Group Psychother 19, 366-381.

13. RABIN, H M (1967). How does co-therapy compare with regular group therapy. Am J Psychiatry 21, 244-255.

14. KANTER, S S (1976). The therapists leadership in psychoanalytically oriented group psychotherapy. Int J Group Psychother 26, 139-147.

15. Walton, H (1971). Small Group Psychotherapy. Penguin Books. London.

16. BECKER, $\mathbf{R}$ E et al (1968). Influence of the leader on the activity level of therapy groups. J Soc Psychol 74, 39-51.

17. Yalom, I D (1975). The Theory and Practice of Group Psychotherapy. Basic Books. New York.

18. Berger, M M (1958). Problems of anxiety in group psychotherapy trainees. $A m J$ Psychother 12, 505-507.

19. ScheIdlinger, $S$ and Pyrke, M (1961). Group therapy of women with severe dependency problems. Am $J$ Orthopsychiatry 31, 776-785.

20. Phillipson, $H$ (1958). The assessment of progress after at least two years of group psychotherapy. Br J Med Psychol 32, 210-221.

21. Malan, D H et al (1976). Group psychotherapy. Arch Gen Psychiatry 33, 1303-1315. 